\title{
Magico-religious Beliefs in Schizophrenia: A study from Eastern part of Nepal
}

\author{
Nidesh Sapkota, Dhana Ratna Shakya, Baikuntha Raj Adhikari, Arun Kurmar Pandey, Pramod Mo- \\ han Shyangwa \\ Department of Psychiatry, BP Koirala Institute of Health Sciences, Dharan, Nepal
}

\section{Correspondence \\ Dr. Nidesh Sapkota \\ Additional Professor \\ Department of Psychiatry, \\ BPKIHS, Dharan \\ E mail: \\ sapkotanidesh@gmail.com}

DOI: http://

dx.doi.org/10.3126/

jcmsn.v12i4.15046

Article received: March $22^{\text {nd }}$ 2016

Article accepted: April $22^{\text {nd }}$

2016

\begin{abstract}
Background \& Objectives: Schizophrenia is one of the commonest psychiatric disorders which require immediate interventions. MagicoReligious beliefs may affect the expression of psychopathology as beliefs are entrenched into human psyche. Local and community beliefs in such phenomena appeared to be a factor in influencing the decision to seek magico-religious treatment. This study aimed (1) to determine attitude of patients and relatives with respect to magico-religious beliefs and its influence on psychopathology, and (2) to examine the relationship between psychopathology and major sociodemographic variables. Materials \& Methods: All 50 consecutive cases of schizophrenia attending psychiatric services during study period were thoroughly evaluated. All the cases were diagnosed as per ICD 10 DCR criteria. The supernatural attitude questionnaire was applied. Results: Fifty cases were studied. Among them, $48 \%$ belonged to the age-group of 25 to 34 years, the majority of them were male $(62 \%), 82 \%$ were Hindus, and $64 \%$ married. Majority of the patients had undergone magico-religious treatment $(\mathrm{n}=$ 35 ). Among the sample, $68 \%$ consulted faith healer and $42 \%$ performed religious treatment during the illness period; $60 \%$ acknowledged personal belief in sorcery, $58 \%$ in ghosts, and $52 \%$ in spirit intrusion. Among them, $20 \%$ believed there was a link between sorcery and mental illness, and $20 \%$ believe spirit could cause mental illness. Among the samples, 38\% found the link between sorcery and abnormal behaviour, 38\% with evil spirit, and $22 \%$ due to planetary influences. Statistically significant association was noted in the belief that rituals can improve patient behaviour and local belief in supernatural influences.

Conclusion: There is a common belief in the relationship between supernatural influences and mental illness among the relatives of the patients. Such beliefs and magicoreligious treatment do occur during the course of the illness.
\end{abstract}

Key words: Magico-Religious belief; Schizophrenia; psychopathology.

Citation: Sapkota N, Shakya DR, Adhikari BR, Pandey AK, Shyangwa PM. Magico-religious Beliefs in Schizophrenia: A study from Eastern part of Nepal. 2016;12(4):150-9.

\section{INTRODUCTION}

Schizophrenia is one of the commonest Psychiatric disorders which require immediate interventions. The life time risk of developing Schizophrenia leading to hospitalization is around $1 \%$. Psychiatric disorders in this region are often attributed to influence of supernatural phenomena, hence many patients are subjected to various kinds of magicoreligious treatments. There is wide held belief that co-occurrences of mental disorders and religious or spiritual problems is found and Schizophrenia is no exception. ${ }^{1}$ Local and community belief in such phenomena appeared to be a factor in influencing the decision to seek treatment by indigenous healer in Schizophrenic patients in this part of the world. Ascribing illness to external malevolent influence e.g. spirits, gods, deities as well as other people has been a very widespread belief. The term MagicoReligious is commonly used to describe beliefs prevalent in a culture concerning various supernatural influences operating in the environment. The treatment by an indigenous healer 
of illnesses considered to be brought about by such influences in known as magico-religious treatment. Culture itself refers to a unique behavioural patterns and lifestyle shared by a group of people and is characterized by a set of values, beliefs, and attitudes towards things in life. $^{2}$ In the great majority of psychiatric conditions, culture plays an important role, which has been found to be both pathogenic (i.e. causing pathology) and pathoplastic (i.e. shaping pathology). However, various aspects of such influences in relation to mental illness have not been adequately researched. In the context of Nepal to the best of our knowledge no such studies have been carried out. This hospital based descriptive study has been selected to strengthen our knowledge and to explore what are the magicoreligious beliefs rooted in this culture and its impact in seeking treatment. We believe that understanding patients and their belief system has tremendous impact in compliance and treatment outcome. So knowing patient as a whole becomes complete only when we can understand to their belief about the cause of the symptoms. We intended to look in this aspect while conducting this project.

\section{Magico-religious belief in psychiatric patients}

Psychiatry as a branch of medicine is heavily influenced by the western concept of mental illness and management. It has been rightly argued that culture plays a role in precipitating the disorder, perpetrating its symptoms and determining how help is sought, and who the main source of help is. It is necessary to understand the cultural aspects in psychiatric disorders. Various types of supernatural influences are thought to be prevalent in a culture for e.g., spirit intrusion or possession, loss of soul, divine wrath, sorcery and black magic or violation of a taboo. Belief in such influences are found in most part of world-North America, the west Indies and among Yoruba people in Africa and Bangladeshis $^{3-5}$ Supernatural influences are commonly invoked as causal explanation for mental illness in many cultures. Fear syndromes attributed to sorcery have been reported among Australian aborigines and in the Burmese population6,7. In India magico-religious beliefs are frequently conjectured as causal explanation of mental illnesses, and consequently services of faith healers are often sought for treatment of mental disorder ${ }^{8-9}$. Keshvan et al. ${ }^{10}$ made an attempt to study the pattern of psychopathology attributable to such influences. Malhotra and $\mathrm{Wig}^{11}$ and Boral et al. ${ }^{12}$ have studied the attitude of the community towards such beliefs and magico-religious treatments.

Magico-religious belief in Schizophrenia patients

Few studies have been carried out in India in which attitudes towards supernatural influences and their role in causing mental illnesses. Studies by Chakraborty and Bhattacharya, have shown that the general population, including subject from urban background, believed to a variable extent that supernatural influences like demonology and black magic can cause mental illness. ${ }^{9}$ Kulhara et al. ${ }^{13}$ conducted a study in North India on MagicoReligious beliefs in schizophrenia. The effects of such Magico-Religious beliefs on psychopathology and treatment seeking behaviour were explored. Supernatural Attitude Questionnaire was administered to the key relatives of the patients to ascertain their beliefs about various supernatural phenomena and Magico-Religious treatments. The finding showed that the majority of the patients had undergone Magico-Religious treatment (23/40). The belief in supernatural influences was seen in patients' relatives from urban background and with adequate education, and treatment based upon such belief is sought to a considerable extent in such cases.

\section{Nepalese context}

In Nepal, though similar culture and beliefs are shared there is lack of research in this field. Family members including relatives and neighbor have considerable influence on the patients care and choice of treatment. At the same time, due to the nature of the illness patients is unaware about the illness and their belief in supernatural influences could be one of the reasons in seeking MagicoReligious treatment. The study conducted in the department of psychiatry regarding the influence of magico-religious belief on psychopathology among patients with manic episode also reveals that there is a common belief in relationship between supernatural influences and mental illness among the relatives of the patients. ${ }^{14}$

\section{MATERIALS AND METHODS \\ The setting and patient selection}

This study was approved by the Ethics Review Committee of the Institute. It was conducted at the department of Psychiatry, B. P. Koirala Institute of Health and Sciences, Dharan Nepal. It is a tertiary level, referral health institute in eastern part of Nepal. This was a cross sectional study; 50 patients with diagnosis of Schizophrenia as per ICD 10 DCR criteria were recruited by purposive sampling. 
We included patients between 15-60 years of age, either sex with diagnosis of Schizophrenia as per ICD 10 DCR criteria. Those patients who refused to participate, primary care taker who refused to give consent or doesn't fulfill the inclusion criteria were excluded from the study.

\section{Exclusion Criteria:}

- Organic mental disorder or any clear CNS involvement e.g. Delirium, dementia.

- Physical illness, which interferes with the assessment.

- Failure to give consent or refusal to participate in study by the patients and /or key informant.

- $\quad$ Age below 15 and above 60 .

- Co-morbid Substance use disorder.

Instruments: The following instruments were used in this study.

1. Criteria for diagnosis of schizophrenia (ICD-10 DCR).

2. Semi-Structured proforma - developed by the department of psychiatry.

3. Supernatural attitude questionnaire ${ }^{13}$

4. Informed consent.

\section{Statistical analysis:}

The coded proformas was collected to the department of psychiatry, BPKIHS. Collected data were entered in Microsoft Excel 2000 and converted it into SPSS PC+ 10 Version for statistical analysis. The descriptive statistics were presented in percentage, proportion, tabular forms. For inferential statistics chi square test with pvalues were calculated at the level of significant at $95 \%$, to find out the relationship between dependent variables and independent variables.

\section{Ethical considerations:}

An informed consent was obtained from the primary care taker. Primary care takers or key relatives are defined as informants of 18 years or more in age who had been living with the patients for at least 1 month before the assessment. Identity of the individuals was kept confidential to maintain their privacy. All the patients received standard care whether he/she participated in the study or not.

\section{RESULTS}

A total of 50 patients (31 males and 19 females) were included in the study. Majority of the patients $(76 \%)$ were below 35 years of age; $82 \%$ of the patients were Hindu followed by $12 \%$ Buddhist. Sixty four percent of the patients were married and only $14 \%$ of the patients completed intermediate
Table 1: AGE

$\begin{array}{lll}\text { Age Interval (years) } & \text { Frequency } & \% \\ 15-24 & 14 & 28 \\ 25-34 & 24 & 48 \\ 35-44 & 10 & 20 \\ 45-54 & 1 & 2 \\ 55-60 & 1 & 2 \\ \text { Total } & 50 & 100\end{array}$

Table2: Sex

$\begin{array}{lll}\text { Sex } & \text { Frequency } & \text { Percent } \\ \text { Male } & 31 & 62 \\ \text { Female } & 19 & 38 \\ \text { Total } & 50 & 100\end{array}$

Table 3: Education

$\begin{array}{lll}\text { Education } & \text { Frequency } & \% \\ \text { Illiterate } & 9 & 18 \\ \begin{array}{l}\text { Literate with no formal } \\ \text { education }\end{array} & 10 & 20 \\ \text { Primary School } & 2 & 4 \\ \text { Middle School } & 6 & 12 \\ \text { SLC } & 15 & 30 \\ \text { Intermediate } & 7 & 14 \\ \text { Graduate } & 1 & 2 \\ \text { Total } & 50 & 100\end{array}$

Table4: Occupation

$\begin{array}{lll}\text { Occupation } & \text { Frequency } & \% \\ \text { Laborer } & 1 & 2 \\ \text { Student } & 12 & 24 \\ \text { Farmer } & 19 & 38 \\ \text { Housewife } & 16 & 32 \\ \text { others } & 2 & 4 \\ \text { Total } & 50 & 100\end{array}$

level of education where as $24 \%$ of them were literate with no formal education. Sixty two percent of the patients were held from rural areas and 56\% of them belonged to the non nuclear family. 
Table5: Family type

$\begin{array}{lll}\text { Family type } & \text { Frequency } & \% \\ \text { Nuclear } & 22 & 44 \\ \text { Non Nuclear } & 28 & 56 \\ \text { Total } & 50 & 100\end{array}$

Table 6: Locality

$\begin{array}{lll}\text { Locality } & \text { Frequency } & \% \\ \text { Urban } & 19 & 38 \\ \text { Rural } & 31 & 62 \\ \text { Total } & 50 & 100\end{array}$

Table 7: AGE

$\begin{array}{lll}\text { Age Interval } & \text { Frequency } & \% \\ \text { 15-24 years } & 10 & 20 \\ \text { 25-34 years } & 17 & 34 \\ \text { 35-44 years } & 2 & 4 \\ \text { 45-54 years } & 9 & 18 \\ \text { 55- 64 years } & 6 & 12 \\ \text { 65 years above } & 6 & 12 \\ \text { Total } & 50 & 100\end{array}$

Table 8: Sex

$\begin{array}{lll}\text { Sex } & \text { Frequency } & \% \\ \text { Male } & 34 & 68 \\ \text { Female } & 16 & 32 \\ \text { Total } & 50 & 100\end{array}$

Table 9: Education

$\begin{array}{lll}\text { Education } & \text { Frequency } & \% \\ \text { Illiterate } & 6 & 12 \\ \text { Literate with no } & 14 & 28 \\ \text { formal education } & & \\ \text { Primary School } & 2 & 4 \\ \text { Middle School } & 7 & 14 \\ \text { SLC } & 14 & 28 \\ \text { Intermediate } & 6 & 12 \\ \text { Graduate } & 1 & 2 \\ \text { Total } & 50 & 100\end{array}$

Table10: Occupation

$\begin{array}{lll}\text { Occupation } & \text { Frequency } & \% \\ \text { Business } & 2 & 4 \\ \text { Student } & 9 & 18 \\ \text { Farmer } & 18 & 36 \\ \text { Housewife } & 18 & 36 \\ \text { Service } & 1 & 2 \\ \text { Others } & 2 & 4 \\ \text { Total } & 50 & 100\end{array}$

Table11: Socio economic condition:

$\begin{array}{lll}\text { SEC } & \text { Frequency } & \% \\ \text { Low } & 27 & 56 \\ \text { Middle } & 14 & 28 \\ \text { Upper } & 9 & 18 \\ \text { Total } & 50 & 100\end{array}$

Table 12: Relationship

$\begin{array}{lll}\text { Relation } & \text { Frequency } & \% \\ 1^{\text {st }} \text { Degree family } & 46 & 92 \\ \text { Relatives } & 3 & 6 \\ \text { Friends } & 1 & 2 \\ \text { Total } & 50 & 100\end{array}$

Table 13: Delusions and hallucinations of the patients $(\mathrm{n}=50)$

$\begin{array}{ll}\text { Variables } & \text { Present, } \mathrm{n}(\%) \\ \text { All types of hallucinations } & 34(68) \\ \text { Delusions of reference } & 30(60) \\ \text { Delusions of persecutions } & 38(76) \\ \text { Religious Delusions } & 8(16)\end{array}$

Regarding the occupation $38 \%$ were farmers and $32 \%$ were house wife.

Socio-demographic variables of Key relatives:

Of the 50 key relatives 46 persons accompanying the patients were the family members and among them 14 were spouses, 26 were parents and 6 were siblings. Remaining 3 were other relatives such as uncle, aunt and nephew. One was a paid care taker staying with the patient. The majority of the relatives $(60 \%)$ had 10 years or more of formal 
education. Twenty eight percent of them have passed SLC which is regarded as the Iron Gate in Nepal. Regarding the occupation $36 \%$ of the key relatives were farmers and housewife. When socioeconomic condition was assessed $56 \%$ of the key relatives belonged to low socioeconomic class. All of the relatives comprehended the Supernatural Attitude Questionnaire.

\section{Clinical Findings}

Among the type of Schizophrenia paranoid was the commonest (70\%) followed by undifferentiated and Catatonic. Regarding the psychotic symptoms 34\% of them had hallucination and Delusion of persecution was the commonest type of delusion $(76 \%)$.

\section{Supernatural Attitude Questionnaire: ${ }^{13}$}

When supernatural attitude questionnaire applied to the key relatives, $60 \%$ of the key relative acknowledged personal belief in Jadu Tona (sorcery), $58 \%$ in Bhoot Pret(ghosts/evil spirit), $52 \%$ in spirit intrusion. When asked about the role of such influence in causing mental illness $20 \%$ of them believed that there is a link between sorcery and mental illness, $20 \%$ of them believed that evil spirit can cause mental illness and 20 of them held the belief that spirit intrusion can cause mental illness. Sixteen percent of the key relatives were of the opinion that divine wrath (Devi Devata Prakop) can cause mental illness, $12 \%$ of them believed that dissatisfied or evil spirit can cause mental illness and $14 \%$ were in the opinion that retribution of bad deeds in previous life can cause mental illness. While trying to explore about the link between the supernatural influences and mental illness $38 \%$ of them believed that the abnormal behaviour are due to the influence of sorcery, $38 \%$ evil spirit, $34 \%$ to spirit intrusion, $36 \%$ divine wrath, $22 \%$ to planetary influences and $26 \%$ to dissatisfied/evil spirit.

\section{DISCUSSION}

Nepal is a small country having more than one hundred ethnic groups and diverse socio-cultural background. Majority of the Nepalese population are Hindus and shares common cultural heritage with Indian though it is sandwiched between two Asian giants; India and China. In our context family members take most of the treatment decision for the patient; hence understanding personal beliefs and beliefs of the care takers about the cause of mental illness is useful for making treatment decision and making long term plan for the patient. It is pertinent for the clinician to understand the traditional beliefs about mental illness in contrast to western biomedical models for proper adherence with the treatment plan and maintaining compliance. This study has evaluated role of magico-religious beliefs in causation of mental illness, personal beliefs in causation of symptoms and help seeking behaviour of patient with Schizophrenia. We have used supernatural attitude questionnaire instrument developed Kulhara $\mathrm{P}$ et $\mathrm{al}^{13}$ from one the prestigious Institute in North India as this can closely reflect the magico-religious beliefs in causation of mental illness or change in behaviours of the Nepalese population. As significant number of patients from north side of India bordering Nepal also utilize Psychiatric services of this Institute so this instrument is quite appropriate for our setting. We evaluated magico-religious beliefs of the patients and its role in causing mental illness or current symptoms by asking questions in yes or no format.

Among the key relatives $42 \%$ had completed more than 10 years of formal education, this reflects improvement in literacy rate of the country however similar kind of study carried out by Kulhara $\mathrm{P}$ et $\mathrm{al}^{13}$ in North India reveals $70 \%$ of the key relatives had 10 years or more of formal education. That study was conducted in big city of India with higher literacy rate than ours; this could be one of the reasons for higher literacy rate in their study and other reason could be majority of the key relatives belonged from rural areas where access to education is limited comparing urban counterparts. Majority of the patients were males, unemployed, Hindu and from non-nuclear family from rural background. This findings is consistent with the findings observed by Kate $\mathrm{N}$ et al. ${ }^{15}$ This study reveals that magicoreligious beliefs are quite common in Nepalese community and sorted different healing measures in the community. When supernatural attitude questionnaire applied to the key relatives, $60 \%$ of the key relative acknowledged personal belief in Jadu Tona (sorcery), $58 \%$ in Bhoot Pret(ghosts/evil spirit), $52 \%$ in spirit intrusion. In comparison to other studies of similar kind conducted in Indian subcontinent by Kulhara et $\mathrm{al}^{13}$ and Kate $\mathrm{N}$ et a $1{ }^{15}$ our figure is higher; this could be due to cross cultural variation across two countries, interview technique and more of the samples belonged from rural areas where alternative therapeutic approached based on religious beliefs are supposed to be more than the urban areas. We have tried to explore about 
Table : 14 Supernatural Attitude Questionnaire key relatives

\begin{tabular}{|c|c|c|}
\hline Questions & Frequency (n) & Percentage (\%) \\
\hline \multicolumn{3}{|c|}{ Do you believe in sorcery/witchcraft? } \\
\hline Yes & 30 & 60 \\
\hline No & 20 & 40 \\
\hline Total & 50 & 100.0 \\
\hline \multicolumn{3}{|c|}{ Do you believe in Ghosts/Evil Spirits? } \\
\hline Yes & 29 & 58.0 \\
\hline No & 21 & 42.0 \\
\hline Total & 50 & 100.0 \\
\hline \multicolumn{3}{|c|}{ Do you believe in Spirit Intrusion? } \\
\hline Yes & 29 & 58 \\
\hline No & 21 & 42 \\
\hline Total & 50 & 100.0 \\
\hline \multicolumn{3}{|c|}{ Do you think sorcery/Witch Craft can cause mental illness? } \\
\hline Yes & 10 & 20 \\
\hline No & 40 & 80 \\
\hline Total & 50 & 100.0 \\
\hline \multicolumn{3}{|c|}{ Do you think Ghosts/Evil Spirits can cause mental illness? } \\
\hline Yes & 10 & 20 \\
\hline No & 40 & 80 \\
\hline Total & 50 & 100.0 \\
\hline \multicolumn{3}{|c|}{ Do you think spirit intrusion can cause mental illness } \\
\hline Yes & 10 & 20 \\
\hline No & 40 & 80 \\
\hline Total & 50 & 100.0 \\
\hline \multicolumn{3}{|c|}{ Do you think Divine Wroth can cause mental illness? } \\
\hline Yes & 8 & 16 \\
\hline No & 42 & 84 \\
\hline Total & 50 & 100.0 \\
\hline \multicolumn{3}{|c|}{ Do you think adverse planetary/Astrological influences can cause mental illness? } \\
\hline Yes & 6 & 12 \\
\hline No & 44 & 88 \\
\hline Total & 50 & 100.0 \\
\hline \multicolumn{3}{|c|}{ Do you think dissatisfied or evil spirit can cause mental illness? } \\
\hline Yes & 6 & 12 \\
\hline No & 44 & 88 \\
\hline Total & 50 & 100.0 \\
\hline
\end{tabular}


Table 14 Contd.

Do you think that mental illness is as retribution of a bad deed in previous life?

$\begin{array}{lll}\text { Yes } & 7 & 14 \\ \text { No } & 43 & 86 \\ \text { Total } & 50 & 100.0 \\ \text { Do you think patient's behaviour are due to: } & & \\ \text { Sorcery/Witchcraft } & \text { Frequency (n) } & \text { Percentage (\%) } \\ \text { Yes } & 19 & 38 \\ \text { No } & 31 & 62 \\ \text { Total } & 50 & 100.0\end{array}$

\section{Ghost/Evil Spirits}

Yes

$19-38$

No

$31-62$

Total

50

100.0

\section{Spirit Intrusion}

Yes

$17 \quad 34$

No

66

Total

50

100.0

Divine Wroth

Yes

No

18

36

Total

32

64

50

100.0

Planetary Influences

Yes

No

11

22

Total

39

78

50

100.0

\section{Evil Spirits}

Yes

$13-26.0$

No

Total

50

100.0

Do you think Puja/Rituals/ Jhad-phoonk can change behaviour?

Yes

$$
9
$$

41

18

No

50

82

Total

50

100.0

Did you consult a faith healer?

Yes

No 
Table 14 Contd.

Was Puja/Ritual/Jhad-phoonk performed with a view of making better?

Yes

No

Does the patient believe or talk about:

$\begin{array}{lll}\text { Sorcery/Witchcraft } & \text { Frequency (n) } & \text { Percentage (\%) } \\ \text { Yes } & 16 & 32 \\ \text { No } & 34 & 68 \\ \text { Total } & 50 & 100.0\end{array}$

\section{Ghosts/Evil Spirits}

$\begin{array}{ll}\text { Yes } & 17\end{array}$

No 33

Total

50

\section{Spirit Intrusion}

Yes

No

Total

$\begin{array}{ll}19 & 38 \\ 31 & 62 \\ 50 & 100.0\end{array}$

\section{Divine Wroth}

$\begin{array}{ll}\text { Yes } & 19 \\ \text { No } & 31 \\ \text { Total } & 50\end{array}$

\section{Planetary Influences}

Yes 13

No

Total

$19 \quad 38$

$31-62$

$\begin{array}{ll}31 & 100.0\end{array}$

\section{Evil Spirit}

Yes

No

Total

13

37

50

Did he talk or believe in these things before falling ill ?

Yes

No

Total
18

32

50
34.

66.

100.0

Did patients visit faith healer at his/her request

$\begin{array}{lll}\text { Yes } & 15 & 30 \\ \text { No } & 35 & 70 \\ \text { Total } & 50 & 100.0\end{array}$

Community believe in such influences?

Yes

No

Total
13

37

50
36

64

100.0

Does the patient belong to specific religious sect ?

\begin{tabular}{lll} 
Yes & 7 & 14 \\
No & 43 & 86 \\
Total & 50 & 100.0 \\
\hline
\end{tabular}


Table 15: Association between magico-religious treatment group and non magico-religious treatment group with different variables:

Parameters Magico-religious t/t group Non Magico-religious t/t group Chi sq P value

Relatives believe in Supernatural influences

$\begin{array}{lrrrr}\text { Yes } & 10 & 20 & 0.397 & 0.529 \\ \text { No } & 5 & 15 & & \end{array}$

Relatives believe in Spirit intrusion

$\begin{array}{lllll}\text { Yes } & 10 & 19 & 0.661 & 0.416\end{array}$

No

5

16

Relatives believe that patient's behavior is because of planetary influences( Grah-Nakechatra)
Yes
6
0
15.909
$0.000^{*}$
No 9
35

Relatives believe rituals can improve patient's behavior
Yes
7
2
11.93
$0.001^{*}$

No

8

33

Local belief in supernatural influences
Yes
9
4
12.87
$0.000 *$

No

6

31

Relatives performed rituals like puja,jhad-phook to improve patient's behavior recently
Yes
12
17
4.258
$0.039^{*}$
No
3
18

the etiological attribution for the change in behaviour or the cause of mental illness; more than two third of the population in combination believed that due to the influence of sorcery, evil spirit, spirit intrusion, divine wrath (Devi Devata Prakop) and dissatisfied or evil spirit can cause mental illness. Our finding is consistent with the finding observed by Adewuya $\mathrm{AO}$ et $\mathrm{al}^{16}$ and Saravanan et $\mathrm{al}^{17}$ conducted earlier in different sultural settings. This shows that public perceptions haven't changed and it is equally seen across the different cultures. Hence integrating awareness raising programmes in the community is important for the family members and the patient for initiating early medical intervention. In our study, only $18 \%$ of the primary care takers believed that magico-religious treatment can change and improve patient's behaviour but it was actually carried out in $58 \%$ of the cases. Similar observation was noted in the studies cited above. This shows there are some other factors prevalent in the community that decides about the

help seeking behaviour.

\section{CONCLUSION}

This is a small study conducted on a hospital based sample done at BPKIHS, Dharan, eastern part of Nepal, but it may be pertinent to summarized the important findings as follows:

1. There is a common belief in relationship between supernatural influences and mental illness among the relatives of the patients.

2. Such beliefs and magico-religious treatment does occur during the course of the illness even though the patient on psychiatric care.

3. It is pertinent to address the cultural issues while treating the patient 


\section{REFERENCES}

1. Goodwin F, Jamison K. Manic depressive illness. New York, Oxford University press, 1990, p. 302.

2. Bhugra D, Ranjith G, Patel V. Handbook of Psychiatry. A South Asian Perspective- Nov. 2004.

3. Lambo TA: Role of cultural factors in paranoid disorders among the Yoruba Trebe. J Ment Sci. 1955;101:239-66.

4. Tinling Dc: Voodoo, Witchcraft and Madness. Psyhcosom Med. 1967 ;29:483-41. DOI: 10.1097/00006842196709000-00007. PMID: 6059919.

5. Wintrob R. The influence of others: Witch and root work as explanation of behaviour disorders. J Nerv Ment Dis. 1973;156:318-26. DOI: 10.1097/00005053-19730500000005

6. Reser JP, East Well HD. Labeling and cultural expectations: Shaping of Sorcery Syndrome in Aboriginal Australia. J Nerv Ment Dis. 1981; 169:303-310. DOI: 10.1097/00005053-198105000-00007.

7. Spiro ME. The psychological function of witchcraft belief: The Burmese Case; in Candill W, Lin T (eds): Mental Health Research in Asia and Pacific. Honululu, East West Center Press, 1969.

8. Chakraborty A. An analysis of Paranoid Symptomatology. Indian J Psychiatry. 1964;6:172-84.

9. Chakrayborthy A, Bhattacharya D. Witcheraft beliefs and persecutory ideas in Bengali Culture. Indian $\mathrm{J}$ Soc Psychiatry. 1985;1:231-43.

10. Keshvan MS, Narayan HS, Gangadhar BN. Bhanmati Sorcery and psychopathology in South Indian - A clinical study. Br J psychiatry. 1989:154:218-20. DOI: 10.1192/ bjp.154.2.218.

11. Malhotra H, Wig NN. How does the public manage deviant behaviour ? Indian J Psychiatry. 1975;13:95-8.

12. Boral GC, Bagehi R, Nandi DN. An Opinion Survey about the causes and treatment of mental illness and the social acceptance of the mentally ill people. Indian J Psychiatry. 1980;22:235-8. PMID: 22058472.

13. Kulhara P, Avasti A, Sharma A. Magico-religious beliefs in Schizophrenia: A study from North India. Psychopathology. 2000, 33:62-8. DOI: 10.1159/000029122. PMID:10705248.

14. Sapkota N, Pandey AK, Adhikari BR, Shyangwa PM, Shakya R. Magico-Religious beliefs among primary care takers of manic patients. J Psychiatrists' Association of Nepal. 2013;2(1):7-13.

15. Kate N, Grover S, Kulhara P, Nehra R. Supernatural beliefs, aetiological models and help seeking behaviour in patients with Schizophrenia. Ind Psychiatry J. 2012;21:4954.

16. Adewuya AO, Makanjuola RO. Lay beliefs regarding causes of mental illness in Nigeria: Pattern and correlates. Soc Psychiatry Psychiatr Epidemiol. 2008;43:336-41. DOI: 10.1007/s00127-007-0305-x. PMID:18273532.

17. Saravanan B, Jacob KS, Johnson S Prince M, Bhugra D, David AS. Belief models in first episode Schizophrenia in South India. Soc Psychiatry Psychiatr Epidemiol. 2010;45:175-82. 